\title{
Learning with the use of distance learning technologies or what digital tools should a teacher possess?
}

\author{
D.M. Voronin ${ }^{1 *}$, A.V. Nechaev ${ }^{2}$, and E.G. Voronina ${ }^{3}$ \\ ${ }^{1}$ State Humanitarian University of Technology, Orekhovo-Zuyevo, Russia \\ ${ }^{2}$ University of social Sciences and Humanities, Kolomna, Russia \\ ${ }^{3}$ State Humanitarian University of Technology, Orekhovo-Zuyevo, Russia
}

\begin{abstract}
This work is devoted to the analysis of the digital tools that a modern teacher should possess to implement the educational process using distance learning technologies. Based on the conducted research, the main competencies that a teacher should have to conduct professional activities from the point of view of students were established. Digital tools are urgently needed to implement these competencies. In this paper, we will show our view on the algorithm for using digital tools in the educational process. A teacher should have a wide arsenal of digital tools: be able to use office programs, be able to search, to select, to analyze and to interpret information. To be able to create a teacher's website, record digital audio and video content, to be able to place it for easy access for students, and, of course, be able to use the University's learning management system.
\end{abstract}

\section{A problem statement}

The impact of the introduction of restrictive measures for the spread of SARS-19 on the education system is difficult to overestimate [1], since in the absolute majority of universities were not ready to switch to a completely remote form of work [2]. The main problems were: the lack of equipment of teachers and students with gadgets necessary for work, the low digital literacy of teachers and students, the low speed and poor-quality Internet [3]. There were also significant problems with psychological and physical stress, both teachers and students [4]. For a person who needs to learn digital tools, it is very difficult to simultaneously perform professional duties without fully owning technology [5]. Some of the federal universities that went on vacation before studying with the use of distance education technologies had up to three weeks to prepare for this process, while most of the universities did not have such opportunities, because the management decided to immediately rush into battle [6]. It greatly affected the quality of teaching in the first month of training with the use of distance learning technologies, when teachers, in parallel with their main activities, diligently studied digital tools [7]. According to sociological surveys, the time spent on professional duties, including training in digital tools, increased

${ }^{*}$ Corresponding author: prof-ped.gpa@mail.ru 
by 4-5 hours a day, respectively, the absolute majority of teachers worked more than 12 hours a day [1].

In addition to the main problems mentioned above, there were many other problems [8]: the denial by students and their parents of the effectiveness of distance learning, the lack of video conferencing tools purchased by universities, and the free versions of programs very often failed due to the overload of these tools by a huge number of users [7]. Most teachers could not afford to purchase licenses for video conferencing tools on their own and tried to avoid using them, giving only information and tasks in the LMS [9], as well as links to external resources [1]. Also, the lack of desire to improve themselves [10] and the lack of face-to-face interaction led to an increased number of homework assignments and overload of students.

The problem of improving the educational process [11] in the context of the use of distance learning technologies is very acute [12]. To maximize efficiency, it is necessary to widely use digital tools $[13,14]$ that allow you to optimize the management system of an educational organization [2] and significantly improve the quality of the educational process $[15,16]$. Scientists believe that the approach to digitalization of the educational process should be comprehensive [17], roadmaps should be developed and specific tools [18] for digitalization of the activities of educational organizations should be selected [19].

These studies prove the relevance of developing a list of digital competencies and specific digital tools to improve the quality of the educational process using distance learning technologies [20].

\subsection{The objective of the work}

Over the past year, a large number of publications have been published describing the competencies of teachers, their digital skills, and their knowledge of digital tools and software, but there are few systematic developments on the digitalization of the educational process [21].

The purpose of the work: to develop a map of digital tools of the teacher for the effective implementation of the educational process using distance learning technologies.

Tasks of the work:

1. Identify the deficits of digital literacy of teachers.

2. Choose digital tools for effective educational activities.

\section{Results of the research}

In this study, the following methods of scientific research were used: analysis of literary sources and empirical data, sociological research methods.

As a result of a sociological survey of more than 800 students from 10 pedagogical universities of the Russian Federation, a list of teacher shortages was compiled. The survey was attended by students of the current 2 nd year, as they are the least engaged in university education and only one semester was spent in offline format and one semester in the format of using distance educational technologies. This makes it possible to evaluate individual elements of the mixed learning system less biased. The second aspect was the complete confidentiality of the survey, since the respondents did not need to register to fill out the Google Form and no identification was carried out, this gave us the right to hope for truthful and unbiased answers. Another feature of the survey was the ability to give open answers, with the justification of their own opinion, which brought special interest to the results of the survey.

The students ' answers to the following question "What digital competencies do teachers need were very interesting. $39.4 \%$ of respondents answered the basic skills, $35.2 \%$ - the use 
IT, $9.9 \%$ - the use platforms, $7 \%$ - the use software, $5.6 \%$ - the information of search skills, $4.3 \%$ - the video conferencing, $2.8 \%$ - the good Internet. Based on the answers received, we can say for sure that the level of digital competence among the respondents is very different, since the answers are very different in terms of understanding the question. Another point is that most teachers do not even possess basic digital literacy skills, which is what the students ' answers say.

$63 \%$ of respondents answered "yes" and 37\% - "no" to the question "were you constantly engaged in videoconferencing". This indicator indicates that not all of the teachers who have mastered the tools of videoconferencing used it constantly.

When asked about the location of content and educational materials, $45.6 \%$ of respondents said that educational resources were posted only on the university's platform, and another $54.4 \%$ claim that educational content was posted by teachers on social networks and other platforms.

$40.3 \%$ of teachers worked with students only on the basis of LMS universities, $59.7 \%$ used to communicate with students and social networks and messengers.

Only $11.1 \%$ of the teachers recorded educational video content and uploaded it to the platforms, but at the sometimethe quality of the video content was rated by the students as very high.

When choosing a platform for learning, almost $55 \%$ of respondents chose social media platforms, $28.2 \%$ - university platforms, $15.4 \%$ - both social networks and university platforms are suitable, and $1.4 \%$ of respondents are not satisfied with any of the existing platforms.

As a result of the conducted research, we found out the groups of digital competencies of teachers that are subject to mandatory development: the information search, the work in office applications, the statistical data processing, the ability to create presentations, the ability to use interactive tools for interacting with students, the ability to work in social networks with students; the ability to use video conferencing tools; the ability to create educational video content.

The first group is the search for information, most teachers do not know how to correctly build a query and set keywords in the search. Let's name the most popular databases for information search:

Inspec Analytics-allows you to visualize the search results, compare the results obtained, based on the names of institutions, the names of authors and topics by the number of publications.

The Russian Science Citation Index is a database containing materials from reputable Russian journals that are selected by experts based on clearly defined criteria. This is an extensive database with the largest representation of publications that relate to relevant subject areas for Russian science.

Scopus is the largest single database of international research, contains abstracts and information about the citation of peer-reviewed scientific literature, with convenient tools for searching, analyzing and visualizing data.

Springer and SpringerLink is a publishing house with a huge database of abstracts and full-text materials of scientific research, journals and books.

Web of Science is one of the most authoritative scientometric abstract databases of journals and scientific research. This platform contains world-class scientific materials.

Archive of journals of the Russian Academy of Sciences-database of journals of the Russian Academy of Sciences, since 2017, access to electronic versions of journals is provided on the platform elibrary.ru and libnauka.ru.

Cambridge University Press is a unique collection of research and academic information, with more than 1,600,000 scientific articles and more than 36,000 books. 
Oxford University Press is a full-text database of Oxford University journals. It contains materials on social and humanitarian sciences, natural and technical sciences, computer science, medicine, healthcare, and much more.

The University Information System Russia is an electronic library and database of information in the field of economics, management, sociology, linguistics, philosophy, philology, international relations and other humanities.

Electronic library system of the Lan Publishing House. A high-quality electronic library, with a large database of both textbooks and scientific journals.

The electronic library system "Urait" is a virtual reading room for economic, legal, humanitarian, engineering and natural science fields.

CyberLeninka is a scientific electronic library built on the Open Science paradigm, the database consists of high-quality scientific research, and has convenient search tools.

The second competence is the improvement of work in office applications, studies show that some teachers know only a small part of the functionality of even the Microsoft Word program. The minimum amount of digital competencies for teachers is the confident use of the following programs: Microsoft Word, Microsoft Excel, Microsoft PowerPoint, Microsoft Whiteboard, Microsoft Outlook.

The third competence-statistical data processing, implies basic skills in data processing, at the basic level it is knowledge of determining the correspondence of a sample to the general population, variance analysis, correlation analysis, determining the significance and significance of changes that occurred during the experiment using parametric and nonparametric criteria. If we take an advanced level it's necessary to analize big data, the use of regression analysis, and so on. For the basic level, we offer to partially study the functionality of the programs Statistica, SPSS, R and Excel, which are used to solve the above tasks.

The fourth competence-the ability to create presentations implies a graphic and visual representation of educational content and scientific research. The most common program used for visual materials is Microsoft PowerPoint and graphics from Microsoft Excel, but there are many other programs that significantly expand the functionality of building and presenting data. We suggest using the following tools:

Google Data Studio is a very simple and convenient free data visualization service that allows you to quickly summarize, analyze and visualize data, and contains an interactive control panel. The service is constantly updated. You can configure the viewing and publishing of reports, see changes in data sources and reports, and share information.

Power BI is a free platform from Microsoft, with which you can easily and quickly process different data. It helps to visualize reports, analyze data and correctly evaluate marketing indicators, and allows you to build detailed and general reports for the requests of the manager. You can download data from different sources.

Infogram is one of the most well-known and simple data visualization tools. Which allows you to build interactive charts and graphs.

Prezi is a web service it allows you to create interactive multimedia presentations with a non-linear structure.

The fifth competence is the ability to use interactive tools for interacting with the student. In this competence, we will also present digital tools that will help you implement it.

The Mentometer is a tool for creating presentations, organizing meetings, events, and making interactive content. It helps you to make any activity interactive with instant surveys. It is extremely convenient to export data to Microsoft Excel and Microsoft PowerPoint. 
Quizziz-the teacher creates a survey, students answer the questions, while there is no opportunity to see the answers of others, the data obtained during the survey can be uploaded to Microsoft Excel.

Kahoot is a convenient and simple service for creating online quizzes, tests and surveys.

Plickers is an online service that allows you to conduct a survey and collect data in the classroom using QR codes, a big plus is the instant result of the survey.

Socrative is an online service for conducting quizzes and interactive games in the classroom. A special feature is the use of applications for mobile devices and the absence of the need for registration for students.

Miro is an online collaboration platform. It give an opportunity to explore brainstorming and design discussions to process design, complex systems, and prototyping.

Padlet is an online whiteboard that allows you to choose the design of a virtual whiteboard, organize collective activities in real time and work with visual content, place materials both from any medium and from the Internet.

The sixth competence is the ability to work in social networks with students. The sociological survey showed interesting data. Instagram Facebook - 100\%, followed by Instagram 57\%, Telegram 16.9\%, Twitter - 6\%, Facebook - 6\%, Odnoklassniki - 2\% became the clear winner of the question " what social networks do you use?". Accordingly, teachers should use those networks that have the largest representation of students. Also an important element is the design and content of the teacher's website.

The seventh competence is the ability to use video conferencing tools.

In Google Hangouts, up to 10 people can communicate via video call. The service also supports simultaneous voice chat and allows participants to join the conference either via email or via a shared link.

Cisco Webex Meetings is the company's web conferencing app, free of charge, supports up to 50 video conference participants, calls are limited to 40 minutes. However, there is no limit on the number of calls you can make, as a gift you get $1 \mathrm{~GB}$ of cloud storage. There is support for features such as screen sharing, video recording, polls, voice detection, and file sharing. All meetings and recordings are fully encrypted. In practice, the registration process is very difficult.

Zoom Meetings-users can hold video conferences with up to 100 participants for free, but conferences with 3 participants or more are limited to 40 minutes. The app allows participants to join via the Internet, special apps, browser extensions, and mobile devices using the iPhone and Android apps. You can record video or audio locally and share the screen image with other conference participants.

Skype-suitable for video conferencing for small groups of up to 50 people In practice, when joining more than 15 people, it begins to hang heavily.

Jitsi is a free project, it should be noted that there is theoretically an "unlimited" number of service participants, but based on practice, joining more than 35 people to a video conference causes the system to overload and it begins to hang. Screen sharing and chat is possible.

Facebook Meeting Room is a completely new tool that almost does not load the system, supports video conferencing for up to 50 people. There is the possibility of showing the screen. The disadvantages are the lack of video recording in the program and the lack of chat.

Discord was once created as a free messenger with support for VoIP and video conferencing for gamers. Now this service has become much more popular, even among the business audience. The great advantage of Discord is that it is free.

Also, if you have a small group, do not forget about the possibility of using WhatsApp, Viber, FreeConference. 
If you have the opportunity to purchase paid solutions, then the most attractive option is to use Microsoft Teams, Zoom, Skype for business, TrueConf, MyOwnConference

The eighth competence is the ability to create educational video content, it consists of several parts at once. First, in order to create a training video, you need to record it. You can use a variety of different programs to record videos, but we want to highlight some of them:

CamStudio - "Open source" is a very simple program for recording video from the screen with audio support, supports recording in several formats.

Jing can shoot videos and take screenshots. It is possible to add text boxes, arrows or rectangles to highlight the right moments, record audio. The recording results can be sent to Screencast.com, Flickr, Twitter, and other web services.

Webinaria-the record is kept in the format avi with the possibility of further conversion to .flv, there are hot buttons to start / stop recording. There is an interesting function of combining two video sources (for example, webcam and screen recording).

Windows Media Encoder is a powerful application for capturing audio and video content with multi-channel high-quality sound, supports HD.

Using the iSpring program will give you the opportunity to record a high-quality video directly from Microsoft Power Point, with the ability to demonstrate a presentation, process and overlay video and audio tracks [12].

The next step is usually the processing of video materials, for which we recommend the following programs:

DaVinci Resolve is a professional video editor, focused on post-production and has a huge number of tools for adjusting the image and sound. For the free version, there are several restrictions that the average user is likely to be invisible.

Shotcut-an editor that will be equally good for both beginners and more experienced users, has a flexible, intuitive interface and great support for video formats, transitions, combinable filters and export are also available not only in a given format, but also for a specific device.

Lightworks is a program that supports multi-camera editing and color correction.

OpenShot is able to work with various video formats, supports an unlimited number of tracks. It also has a good gallery of transitions, filters, and titles.

Movie Maker is a simple yet functional editing app that lets you easily combine multiple videos, edit them, and add different effects. It offers a whole set of filters, transitions, and music, as well as allows you to change the playback speed and apply a blur effect to the video [10].

After creating the video material, you will need to upload it to the video hosting service in order for your students to have access to the materials. YouTube is the most popular video hosting service in the world, and it is used by billions of visitors from all over the world every day. You can post any video on YouTube, subject to copyright, subject to content censorship. Also worth noting is a new video hosting service - Yandex. Efir, which also hosts videos for free, but there is censorship on content and copyright. An interesting tool is Vimeo-a popular video hosting service that has the main distinguishing feature-the complete absence of advertising. Do not forget about the possibility of free video posting on Vkontakte, Odnoklassniki, Video mail, Facebook. Also popular Russian video hosting is RuTube, which also has great opportunities for hosting training videos.

\section{Conclusions}

As a result of our research, we have proposed specific digital tools that will significantly improve the effectiveness of teachers ' work. In conclusion, we will focus on particularly necessary aspects in the work of the teacher. 
Analyzing the group of information search skills, it should be noted that relevant data search is possible in professional databases. It is mandatory for the teacher to have knowledge of interdisciplinary, scientific and subject databases that contain relevant professional information.

The work of teachers in office applications involves the free use of text editors, tools for drawing, image processing, the ability to work in email applications, the ability to use applications for working with office equipment.

Skills in the field of statistical data processing include the ability to verify the conformity of a sample to the general population, variance analysis, determining the reliability of experimental data by using parametric and nonparametric criteria, as well as determining correlation and concordance coefficients, skills in regression analysis and big data analysis are desirable.

The ability to create presentations involves the skills of using text information, image processing, the use of dynamic objects, the ability to visualize data, and the construction of graphs and diagrams.

The ability to use interactive tools of interaction with the student includes the use of interactive whiteboards, means of conducting interactive surveys, sociological surveys, the organization of team work, the organization of project activities, the introduction of elements of gamification in the educational process.

The skills of working with students in social networks and the Internet are of great importance for obtaining an educational result, which gives a significant level of motivation to students. To do this, the teacher must own messengers and actively use social networks, and students are also very interested in placing educational materials outside the LMS.

The use of video conferencing tools not only allows you to make video calls, but also allows you to conduct classes in small groups, trainings, and use interactive tools with instant results.

The ability to create educational video content consists of five main stages: development of video content design, recording of educational video content, video and audio processing, placement of materials on hosting sites, raising the rating and popularization of materials.

\section{References}

1. D.M. Voronin, A.V. Nechaev, The main competencies of a teacher in mixed learning through the eyes of a student, Problems of modern pedagogical education, 69(1), 129$132(2020)$

2. D.M. Voronin, E.G. Voronina, O.M. Chikhanova, Managing an educational organization in the context of digitalization, Modern health-saving technologies, $\mathbf{1}$, 31-38 (2021)

3. D.M. Voronin, I.V. Kiseleva, E.G. Voronina, Main trends in the education system, Problems of modern pedagogical education, 69(1), 126-129 (2020)

4. R.N. Abramov, I.A. Gruzdev, E.A. Terentyev, U.S. Zakharova, A.V. Grigorieva, University teachers and digitalization of education: on the eve of remote force majeure, University management: practice and analysis, 24(2), 59-74. https://doi.org/10.15826/umpa.2020.02.014 (2020)

5. D.M. Voronin, E.G. Voronina, How did the distance education format affect its quality, Modern health-saving technologies, 3, 7-14 (2020)

6. M.A. Belogash, M.V. Melnichuk, Cognitive aspects of the development of the information and educational environment in higher education in the era of digitalization, Russian Humanitarian Journal, 2, URL: 
https://cyberleninka.ru/article/n/kognitivnye-aspekty-razvitiya-informatsionnoobrazovatelnoy-sredy-v-vysshey-shkole-v-epohu-tsifrovizatsii (2021)

7. D.M. Voronin, Cognitive dissonance: competence of teachers and new reality, Management of the XXI century: socio-economic transformation in the conditions of uncertainty, 287-291 (2020)

8. B. Williamson, R. Eynon, J. Potter, Pandemic politics, pedagogies and practices: Digital technologies and distance education during the coronavirus emergency, Learning, Media and Technology, 45 (2), 107-114. (2020)

9. D.M. Voronin, V.G. Saienko, H.V. Tolchieva, Digital Transformation of Pedagogical Education at the University. International Scientific Conference "Digitalization of Education: History, Trends and Prospects". Atlantis Press, 760-766 (2020)

10. D. Voronin, O. Mishina, O. Zavaltseva, Modern educational organization effectiveness criteria as education quality evaluation and quality enhancement basis, Perspectives of science \& education, 5 (35), 18-26 (2018)

11. M. Hu, K. Arnesen, M.K. Barbour, H. Leary, A Newcomer's Lens: A Look at K-12 Online and Blended Learning, Journal of Online Learning Research, 5, 2, 123-144 (2019)

12. J. Clyde, G. Corpuz, Adapting to the culture of 'new normal': an emerging response to COVID-19, Journal of Public Health, https://doi.org/10.1093/pubmed/fdab057 (2021)

13. D. Voronin, G. Egorova, O. Khotuleva, Expirience in the implementation of blended learning with elements of project activities in the pedagogical Master's program with the example of training teachers of biology, Perspectives of science \& education, 2(38), 155-166 (2019)

14. D.M. Voronin, O.A. Zavaltseva, O.V. Khotuleva, Blended learning in the master's program, EDP Science, 4 (2020)

15. D.M. Voronin, M. Chaychenko, E.G. Voronina, Model for implementing projectbased learning at a regional university, EDP Science, 4 (2020)

16. M.A. Belogash, N.G. Kondrakhina, Metacognition as a tool for personalizing learning in the digital educational environment, Education and law, 5, URL: https://cyberleninka.ru/article/n/metapoznanie-kak-instrument-personalizatsiiobucheniya-v-usloviyah-tsifrovoy-obrazovatelnoy-sredy (2020)

17. D. Uerz, M. Volman, M. Kral, Teacher educators' competences in fostering student teachers' proficiency in teaching and learning with technology: An overview of relevant research literature, Teaching and Teacher Education, 70, 12-23 (2018)

18. S. Hrastinski, What Do We Mean by Blended Learning? TechTrends, 63, 564-569. https://doi.org/10.1007/s11528-019-00375-5 (2019)

19. C.L. Brown, M.A. Comunale, B. Wigdahl, S. Urdaneta-Hartmann, Current climate for digital game-based learning of science in further and higher education, FEMS Microbiology Letters, 365, 21 (2019)

20. J. Hamilton, Plugging the Digital Skills Gap in Northern Ireland, ITNOW, 61, 2, 5455 (2019)

21. T. Crick, Covid-19 and Digital Education: a Catalyst For Change?, ITNOW, 63, 1, 16-17 (2021) 